\title{
Surprising Fact from Indonesia on the Influence of Spiritual Leadership on Employee Voice and Obedience Behavior
}

\author{
Willson Gustiawan ${ }^{1}$, Manh-Trung Phung ${ }^{2}$, Son-Tung Le ${ }^{3}$ \\ \{wgustiawan@gmail.com ${ }^{1}$,pmtrung@vimaru.edu ${ }^{2}$, sontungvimaru@gmail.com ${ }^{3}$ \} \\ Padang State Polytechnic, Padang Indonesia ${ }^{1}$, Vietnam Maritime University, Haiphong Vietnam ${ }^{2}$, \\ Vietnam Maritime University, Haiphong Vietnam ${ }^{3}$, National Yunlin University of Science and \\ Technology, Douliou Taiwan ${ }^{3}$
}

\begin{abstract}
The purpose of this study is to examine spiritual leadership outcomes in terms of voice behavior and obedience or compliance using 244 Indonesian valid samples. In fact, that comprehension of the influence of leadership behavior on employees' cognition, attitude and behavior are considered critically important by scholars, however, there are still research gaps existing in this area. Surprisingly, the results show that although spiritual leadership and mediators of calling and membership are significantly inter-correlated each other, yet these five variables have non-significant correlations with employees' obedience and voice behavior. The influence of the spiritual leadership process across cultures, especially toward voice and obedience behavior is not supported in this study. Possible explanations could be related to the cultural characteristic of employees of these particular samples.
\end{abstract}

Keywords: Spiritual leadership, obedience or compliance behavior, voice behavior

\section{Introduction}

Leadership behavior has unquestionable importance to an organization which takes prominent status that influences its development. During the process of interpersonal and organizational interaction in the workplace, the presence of the leadership behavior will not only affect the working attitude and behavior of employees but also affect the achievement of the objective and working efficiency [1] . A leader plays a key role in a high-efficiency organization. Leadership behavior of managers is one of the important elements in how to make members' feelings and behavior to positively cycle [2].

A comprehensive survey on existing studies, leadership theories are mostly based on the leaders' extrinsic behavior; interactions between leaders and followers; or characteristics, functions, and style of leaders [3]; [4]. Fast-growing global economic environment, leadership behavior is influenced by the national cultural value and various belief systems of religions [5] such as oriental culture with the spiritual background; specific cultural zone [6]; local concept construction [7].

Other studies denote leaders make employees bring their individual subjective consciousness into an organization so as to generate positive psychology and feeling of achievement through building organization goals and team vision. Leadership is a process affecting the members, and makes them obey instructions for the achievement of team objective [8]; [9]; [10]; [11]. 
Voice is a promotive behavior that encourages members to want to advocate constructive suggestions or opinions when there are unsatisfactory circumstances to improve unhealthy organizational situations. It is the employees' willingness that makes creative or improving suggestions on current standard operating procedures. Voice gradually catches the attention of scholars because it emphasizes the expression of constructive suggestions to improve the current situation of an organization [12]. However, although people often have opinions about the company or the work, not everyone wants to speak out all their thoughts [13] and some choose to hind what they really think [14]. The behavior of retaining thoughts, suggestions, and care is silence behavior [15].

Spiritual leadership is one of the strategic leadership theories. The spiritual leadership model is an integrated leader-member interactive relationship model in terms of intervening mechanism of membership and calling. Besides, members will form a belief of ego and selfbased on his role in the organization. These beliefs are strongly related to one's working motivation, attitude and behavior [16]. Spiritual leadership attributes importance to stimulate members' motivation and morality model.

This research probes into whether leadership behavior will elevate employees obedient and voice behavior by spiritual leadership. It is rarely discussed in the past documents, so it is necessary to complement this research gap. Organizational behavior research should focus on the relationship theory and method of intervening mechanism [17], so this research integrates the intervening mechanism such as calling and membership to discuss whether the spiritual leadership model will elevate members' obedient and voice behavior through these intervening mechanisms.

So, this research initiates spiritual leadership and investigates how spiritual leadership behavior will affect members' voice and obedience/compliance behavior, that affected by calling and membership. In addition, those intervening mechanisms between spiritual leadership and voice behavior, the spiritual leadership of leaders will influence member's compliance behaviors and help to make clear whether benevolent leadership can make members willing to voice to organizations and leaders in order to clear up the relationship between variables.

The spiritual leadership model quotes the western research concept. Most of the spiritual leadership research has been conducted in western countries with the western culture background, such as [18]; [19]; and some in Chinese people background such as [20]; [21]; [22]. Moreover, there is virtually no study on the spirituality of Indonesian managers or professionals [23]. Although the extending spiritual leadership model is originated from the western concept, it is believed to be great importance to verify it with another region. This research collected data from Indonesia and Taiwan to discuss the spiritual leadership integration model concept developed. Whether it has cultural universality can increase understanding about related concepts of spiritual leadership.

\section{Developing Research Model}

\subsection{Spiritual leadership and calling and membership}

Discussing leadership must be accompanied by an understanding of motivation. It is appropriate to begin with a discussion of leadership since it essential to an understanding of motivation [18]. Leaders build an expected call of employees' self-value to convince employees that the work is meaningful so they present a prospective attitude to achieve goals. Employees dedicate themselves to the work, they will be influenced by mutual interaction and 
environment so as to change the concept of self, acknowledge the work [24]. When employees accept the value of the working group, he will be more dedicated to the work [18]; [25]. Spiritual leadership not only can help employees to understand the meaning of the work, but also stimulate more interactions between them and their co-workers.

Spiritual leadership focuses on applying meaningful method to help individual and organization taking part in the work together, this process is group socializing process [26] that reduce leader-centered leadership style. Therefore, members produce positive attitude toward herself meaning of the work and sense of membership. Spiritual leaders' behavior should be an example for employees to know deeply about the meaning of work and reduce destructive feelings and promote organizations' performance and happiness [3].

Based on above deduction, assumption 1 and assumption 2 are thus proposed.

H1: Spiritual leadership will affect positively on the call of employees' working meaning. H2: Spiritual leadership will affect positively on employees' membership.

\subsection{Spiritual leadership and voice behavior}

Members' voice behavior originates from Hirschman's proposal of EVL (Exit, Voice, Loyalty) theory. It mainly studies that members may exit, voice and loyalty when facing the dissatisfying situations in an organization. Till now voice has a 30 years history (Dundon, et al., 2004). Early scholars' study on voice mainly focuses on the grumble or complaint when members are dissatisfied with the system or execution [27].

Voice behavior is defined as a behavior that is not requested. It emphasizes the expression of constructive and challenging opinions with the purpose to improve the current situation rather than more critic [12]. It is the ordinary employees in the organization bring forward creative suggestions to the transformation by the down-up method and suggests to modify current standard operation procedure [28]. Furthermore, when some scholars discuss the difference between voice and silence behavior, they defined voice behavior as an opinion expressing behavior [29]; [13]. Therefore, voice behavior is a promotive behavior that employees are willing to propose constructive suggestions or opinions when they are dissatisfied with the measurement and procedures for improving the unhealthy organizational situation; it is beyond a critic behavior. The purpose of voice is for improving the situation of the organization [12] which reflects the members' participation and dedication to the organizations. The voice behavior is performed in various ways: (1) discussing problems with leader or workmates; (2) resorting to tackle the problem; (3) proposing schemes to leaders; (4) seeking help from outside, that are beneficial for the organization's operation and efficiency and can help to improve leader-member relationship [30]. It is constructive for the organization. Hence, it is easier for leaders to accept and appreciate this, thus influence the members' performance evaluation [31].

The study of voice behavior underlines in differentiating environmental and individual elements that influence voice behavior. The former pays more attention to leaders management kennel that the influence whether employees are willing to voice [32]; [28]; [33], the latter concerns personalities and the difference of demographic variables that are related to voice behavior, because in certain organization, some are more willing to pay extra efforts to voice than others [34]. A Leadership style that leaders have the power to decide whether a member will stay or leave is in a working group or a unit will affect members' voice behavior [32]. Otherwise, some scholars study voice behavior, they found that the motivation that employees' voice is not only because of dissatisfaction [12]; [30].

As a result, from the perspective of the relationship between spiritual leadership and the quality of down-up relations, members may care and more support because of leaders are 
tolerant and careful to some members, in turn, members will show gratitude attitude, therefore it can lift the quality of the down-up relationship. spiritual leadership has a positive impact on down-up interaction. Based on the above discussion, assumption 4 is thus proposed:

H3: Spiritual leadership has an impact on members' voice behavior.

\subsection{Spiritual leadership and obedience/compliance behavior}

Influence of leaders can be carried out due to members' obedience, which is mainly achieved by raising members 3 involvements: (1) alternative involvement: means that members comply with leaders because they are afraid of being punished or treat leader improperly; (2) calculative involvement: means that members comply with leaders to draw on advantages and avoid disadvantages; (3) moral involvement: means that members comply with leaders because they are internalized or they agree with leaders. In other words, obedience is the result of leaders' influence, while there are many ways to make members compliance. Obedience is one of the results of leaders' influence [11], it means that target is willing to do what the agent commands, but behaves a little bit of indifferently and only want to do the work with a little effort, at the moment, the agent influences target's behavior rather than attitude and target deems that the decision is not the best processing method, so that the goal cannot be finished efficiently.

Aronson (2004) goes further to describes obedience from reasons behind the behavior. He also thinks that obedience is the behavior that an individual wants to get awards or avoid punishment. Later on, in the power study of leader-member interaction carried out by [35]; [36] using of these two conceptions to divide interpersonal obedient behaviors into behavioral compliance and attitudinal compliance. Behavioral compliance means the superficial obedient stance; while attitudinal compliance means internal compliance.

Relevant study documents about members' obedient behavior and leaders, it is pointed out that from the perspective of role norm and role expectation, leaders and members is a complementary down-up social position. The interaction between both is not only influenced by individual role expectation but also influenced by the role expectations of most people in a specific culture [37].

In conclusion, this research defines obedience as members obey only their commands that belong to behavioral compliance. The occurrence of behavioral compliance is the result of an agent's influence. Compliance includes structural and motivational elements and is related to many variables in the organization. Power structures and members' motivation are developing and operating foundation of the organization so that members' compliance is the essential unit in analyzing an organization. In terms of spiritual leadership, members may gain round-way care and more support because leaders are tolerant and careful to some members, in turn, members will show gratitude attitude which will help in the generation of obedience behavior. Based on the above discussion, assumption 5 is thus proposed:

H4: Spiritual leadership has an impact on members' obedience behavior.

According to the result of research purpose, document discussion, and research assumption deduction, research structure is drawn as below 


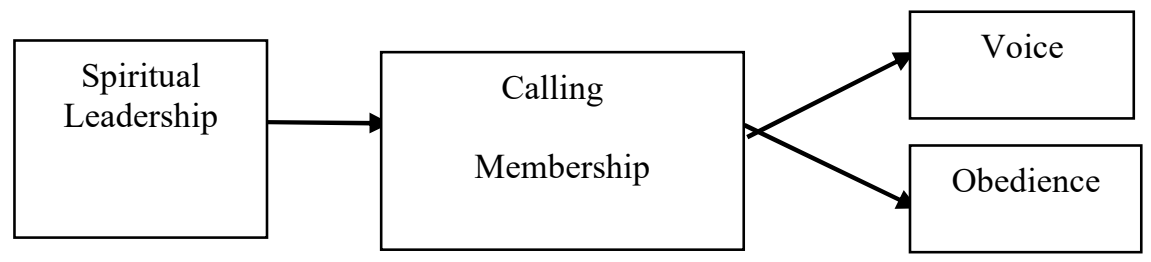

Diagram 1 Structure of the research

\section{Method}

\subsection{Participants}

This study utilizes the convenience sampling method. Data were collected through online and/or directly distributing questionnaires in Indonesia. There were 244 valid responses from Indonesian samples.

There are 244 valid responses. Respondents' mean age is 31.61 with a standard deviation of 8.62 and range from 21 to 57 years old. About $56 \%$ of them are up to 30 years old, $26 \%$ in more than 30 to 40 years old, and the rest in more than 40 years old. Their gender is $50.4 \%$ males and $49.6 \%$ females. Their tenure's mean is 7.22, range between 1 to 35 years and standard deviation 7.15. $22 \%$ of them have up to 1 -year working experience, $36 \%$ more than 1-5 years, and $37 \%$ more than $5-15$, and 5\% more than 15 years. Most of them are at staff level positions (72\%), 16\% at supervisor level, and $12 \%$ at manager level. Their education levels were $53 \%$ bachelor, $21 \%$ graduate, $16 \%$ diploma and $10 \%$ high school.

\subsection{Measures of Variables}

Independent variable: Spiritual leadership: this research adopts a total of 17 subjects of three dimensions' prospect, hope confidence and love compiled by Fry et al (2005). Spiritual leadership theory is a leadership theory based on members' inner motivation, leaders build members' calling and membership through prospect and common understanding of values to elevate organization commitment and productivity [19].

Intervening variable; calling, membership, leader-member relationships: (a) call is a kind of feeling that one's life is meaningful, accomplished and valuable; (b) membership a kind of feeling that one is understood and appreciated. This research adopts a 4-items of calling and 5 items of membership dimension in spiritual leadership scale.

Dependent variable: members' obedient and voice behavior: (a) Obedience. Obedience means that members ought to accept an assignment given by supervisors rather than taking account of some of his own opinions. Therefore, this research defines the definition of obedience as must obedience, comply the leaders' command unconditionally. This research adopts the scale developed in obedient behavior study [38] with a total item of 5; (b) employees' voice behavior [39] that defined voice as stating publicly one's opinions and suggestions about work, including others behavior, thoughts, suggestions, where needs change or alternative scheme related to work, etc. This research adopts the scale of voice behavior [40] with a total item of 10 . 


\section{Result and Discussion}

\subsection{Results}

Table 1 shows the descriptive statistics, bivariate correlations, and Cronbach's alpha of the research variables. The means of the variables range from 3.63 to 4.04 with a standard deviation from 0.436 to 0.582 . The Cronbach's alphas range from 0.763 to 0.899 , which means reach a satisfactory level of variables' reliability.

In regard to correlation, there are positive and negative bivariate correlations between the variables. The spiritual leadership dimensions (vision, hope/faith, and altruistic love) have positive correlations with the mediation variables (calling and membership). Their correlations range from 0.414 to 0.648 and all are significant $(p<0.001)$. Independent variables in terms of vision and altruistic love have a negative correlation with dependent variables in term of voice behavior $(-0.040,-0.018 /$ not significant $)$; as well as in term of obedience behavior $(-0.030$, 0.062 not significant). Hope/faith has a positive but not significant correlation with dependent variables (0.052 and $0.031 /$ not significant). Calling has a positive but not significant correlation with voice and obedience behavior, while membership has positive but not significant with voice behavior, and negative non-significant with obedience behavior. Table 1 tells us that all correlations between spiritual leadership theory variables with dependent variables are not significant.

\begin{tabular}{lllllllllll}
\multicolumn{1}{c}{ Table } & 1. Correlation and Alpha of Research Variables \\
\hline \multicolumn{1}{c}{ Mean } & SD & 1 & 2 & 3 & 4 & 5 & 6 & 7 \\
\hline 1 & Vision & 4.04 & .462 & $(.818)$ & & & & & & \\
2 & Hope/faith & 4.01 & .485 & $.648^{* *}$ & $(.815)$ & & & & & \\
3 & Altruistic love & 3.63 & .548 & $.520^{* *}$ & $.508^{* *}$ & $(.893)$ & & & & \\
4 & Calling & 3.94 & .601 & $.519^{* *}$ & $.706^{* *}$ & $.414^{* *}$ & $(.899)$ & & & \\
5 & Membership & 3.83 & .566 & $.641^{* *}$ & $.565^{* *}$ & $.629^{* *}$ & $.547^{* *}$ & $(.891)$ & & \\
6 & Voice & 3.70 & .436 & -.040 & .052 & -.018 & .061 & .021 & $(.763)$ \\
7 & Obedience & 3.65 & .582 & -.030 & .031 & -.062 & .049 & -.029 & $.334^{* *}$ & $(.787)$ \\
\hline
\end{tabular}

These varieties positive and negative correlations impact research hypotheses. Hypotheses of spiritual leadership (vision, hope/faith, and altruistic love) and mediation variables in terms of calling and membership (H1 and H2) are supported. Hypotheses of spiritual leadership and dependent variables either voice or obedience behavior (H3 and H4) are not supported.

Hierarchical regression analysis is conducted to verify the mediation effect of mediation variables between independents and dependent variables. For dependent variables, voice behavior and obedience have three models. In Model 1, all control variables (age, tenure/work years, position, gender, and education) are entered into regression. Spiritual leadership dimensions in terms of vision, hope/faith, and altruistic love are entered in Model 2. And, finally calling and membership as mediation variables then are entered in Model 3.

The Position of the respondents may influence their voice behavior and obedience behavior for spiritual leadership theory circumstances in their organization. Table 2 shows that the position as control variable has a positive and significant $(\mathrm{p}<0.05)$ beta in all models. Age 
has negative beta; tenure has positive beta, while education and gender have positive and negative betas in the models (but all not significant)

When spiritual leadership dimensions enter into the models, the beta magnitudes are having variety of movements from Model 2 to Model 3 for the two dependent variables. As well as when calling and membership entering into regression, there are inconsistence results of beta (compared to the correlation matrix). It can be concluded that these procedures fall to express the mediation effect of calling and membership between spiritual leadership and voice and obedience behavior.

Table 2. HRA Dependent variable: Voice behavior and Obedience behavior

\begin{tabular}{|c|c|c|c|c|c|c|c|}
\hline \multirow{2}{*}{\multicolumn{2}{|c|}{$\begin{array}{l}\text { Independent } \\
\text { Variable }\end{array}$}} & \multicolumn{6}{|c|}{ Dependent Variable: } \\
\hline & & \multicolumn{3}{|c|}{ Voice behavior } & \multicolumn{3}{|c|}{ Obedience behavior } \\
\hline & & Model 1 & Model 2 & Model 3 & Model 1 & Model 2 & Model 3 \\
\hline Age & & -.087 & -.084 & -.078 & -.050 & -.051 & -.046 \\
\hline Tenure & & .145 & .138 & .131 & .004 & .006 & .001 \\
\hline Position & & $.186^{*}$ & $.188^{*}$ & $.187 *$ & $.213^{*}$ & $.210^{*}$ & $.214^{*}$ \\
\hline Gender & & -.075 & -.066 & -.069 & -.007 & .006 & .001 \\
\hline Education & & 013 & -.001 & -.002 & .078 & .071 & -.068 \\
\hline Vision & & & -.087 & -.098 & & -.024 & -.013 \\
\hline Hope/faith & & & .111 & .074 & & .094 & .055 \\
\hline Altruistic lo & & & -.013 & -.021 & & -.078 & -.062 \\
\hline Calling & & & & .016 & & & -.051 \\
\hline Membership & & & & .055 & & & .074 \\
\hline$\Delta \mathrm{R}^{2}$ & & $.066^{*}$ & .007 & .002 & $.051^{*}$ & .007 & .003 \\
\hline $\mathrm{R}^{2}$ & & $.066^{*}$ & .073 & .074 & $.051 *$ & .058 & .061 \\
\hline $\begin{array}{l}\text { Significant } \\
\text { change }\end{array}$ & $\mathrm{F}$ & 3.345 & .583 & .224 & 2.554 & .566 & .379 \\
\hline
\end{tabular}

Coefficients are Beta

$* \mathrm{p}<0,05$

\subsection{General Discussion}

This research is conducted regarding the importance of leadership in organizational development. Global economic environment changing leadership style under influencing of national cultural value [5]; oriental culture with spiritual behavior and historical background; specific cultural zone [6]. Such a leadership style can influence member behavior [41]; develop relationships [42] and affect performance [43]. Obedience is an important indicator of leadership effectiveness. Voice behavior is another work behavior influenced by leadership style [12]. Spiritual leadership as one of the contemporary leadership theories has attracted may scholars to investigate in the area of organizational behavior. The spiritual leadership model is an integrated model, mediated by calling and membership [18].

Nevertheless, this research finds that there is a surprising result for the Indonesian people. Obviously, this phenomenon meets the assumption of [5], that leadership behavior may depend on national culture background and various belief systems of religions and in terms of the specific cultural zone [6].

Positive and negative correlations occur among research variables for Indonesian people. Spiritual leadership theory with its five dimensions: vision, hope/faith, altruistic love, and the mediator calling and membership have a positive relationship. These results are confirmed with various existing research in spiritual leadership. Voice and obedience behavior also have 
a positive correlation, that strengthens the assumption that the two behaviors have related each other. Surprisingly, the correlations of spiritual leadership theory with voice behavior and obedience behavior are negative and not significant. In other words, spiritual leadership has a opposite relationship with these variables. Spiritual leadership, in this research precisely may reduce employees' behavior in voice and obedience. Spiritual leadership (refer to Table 1).

A Direct effect of all spiritual leadership dimensions (vision, hope/faith and altruistic love) to dependent variable voice behavior has a variety relationship. The vision of a leader has a negative impact on employee's voice behavior. It seems that Indonesian people tend to behave silently. This silence behavior [15]; [32] may appear because of the fright of being replied by their leader, that may affect their performance evaluation. Although employees hold something in their minds regarding their work or even organization, they reluctant to speak [13]. In a strict hierarchy organization, since supervisors have the power to evaluate members' performance, members are more likely to be afraid of being replied by their supervisors because of their suggestions, enterprises will suffer a great loss if its members retain their voice. So, from the perspective of the organization and management, voice behavior is beneficial behavior for the operation procedure and organization because it improves the operation procedure and inserts creative elements in works. However, it will produce more chances for voice when the relationship between leader and members is good and members trust their organizations and leaders. However, members who choose voice excepting to express dissatisfaction, they also hope that the organization can respond to this dis-satisfactory situation and improve the situation [27].

In other hand, hope/faith dimension has positive relationship. In this case, leader should share his/her hope to the subordinates to be brave to talk everything about their work or organization, and convince them with his/her faith that voice behavior would not influence their assessment. While, altruistic love has negative impact to voice behavior. This result tells us that even leader shows his/her love to subordinates, it would not influence their opinion expressing behavior.

In term of obedience behavior, vision and altruistic love dimensions have negative impact. On other hand, hope/faith has positive impact. Actually, obedience is one of the result of leaders' influence [11]. Behavioral compliance is to get the wanted return from agent, or obey under individual or group pressure; otherwise, when agent influences individual selfconception or definition, individual will generate the sincere persuasion so as to change one's internal attitude [44].

It becomes an interesting investigation to discuss. Obedience behavior come from employee's fear of authoritarian leadership. We can say that Indonesian people might not like to obey their leader even though their leader has been trying to share his/her vision or showing his/her love sense to employees. This research finds that for Indonesian people, spiritual leadership lead them to disobedience behavior.

\subsection{Closing remark and future study opportunity}

The research of elevating employee obedience and voice behavior by spiritual leadership becomes important in studying leadership in the organizational behavior field of study. This research collects data from Indonesian with a certain cultural value. Research model has been developed in how to extend spiritual leadership theory can influence voice behavior and obedience behavior. The surprising result is yielded from Indonesia people, the results do not fully support the model. Different culture background is believed as one potential factor to yield this surprising result. 
Some findings in this research should encourage the researcher to conduct further study, especially the reason why spiritual leadership could not affect Indonesian employees' voice and obedience behavior. The next researchers may consider studying the Indonesia culture, what specific culture features [37] that make their voice and obedience behavior less or not influenced by spiritual leadership. Another thing which can consider is to find different research variables, the independent or the mediation variables. We believe such a future study is needed to open this mystery.

Besides that, data that used in this research come from the same source, which may generate common method variance which in turn leads to high estimated biased error. Therefore, in future study, data should collect from different sources to reduce biased error. Common method variance procedure can also be applied to the collected data so that it could be included in the questionnaire design.

\section{References}

[1] J. A. Wagner and J. R. Hollenbeck, Organizational Behavior: Securing Competitive Advantage. New York: Thomson/South-Western, 2005.

[2] J. B. Avey, L. W. Hughes, S. M. Norman, and K. W. Luthans, "Using positivity, transformational leadership and empowerment to combat employee negativity," Leadersh. Organ. Dev. J., vol. 29, no. 2, pp. 110-126, 2008.

[3] R. L. Daft, The Leadership Experience, 4th ed. Mason: South Western, 2008.

[4] P. G. Northouse, Leadership : theory and practice. Thousand Oaks: Sage Publishing, 2001.

[5] L. Fry and M. Kriger, "Towards a theory of being-centered leadership, multiple level of being as context for effective leadership," Hum. Relat., vol. 62, no. 11, pp. 1667-1734, 2009.

[6] J. W. Berry, Psychology of Acculturation. Lincoln: University of Nebraska Press, 1990.

[7] M. W. Morris, K. Leung, D. Ames, and B. Lickel, "Views from the inside and outside: Integrating emic and etic insight about culture and justice judgments," Acad. Manag. Rev., vol. 24, no. 4, pp. 781-796, 1999.

[8] J. Yang and K. W. Mossholder, "Examining the effects of trust in leaders: A bases-andfoci approach," Leadersh. Q., vol. 21, no. 1, pp. 50-63, 2010.

[9] Y. Lapidot, R. Kark, and B. Shamir, "The impact of situational vulnerability on the development and erosion of followers' trust in their leader," Leadersh. Q., vol. 18, no. 1, pp. 16-34, 2007.

[10] C. S. Burke, D. E. Sims, E. H. Lazzara, and E. Salas, "Trust in leadership: a multi-level review and integration," Leadersh. Q., vol. 18, pp. 606-632, 2007.

[11] G. A. Yukl, Leadership in Organizations. Upper Saddle River: Prentice Hall, 2002.

[12] J. LePine and L. Van Dyne, "Predicting Voice Behavior in Work Groups," J. Appl. Psychol., vol. 83, pp. 853-868, Dec. 1998.

[13] L. Van Dyne, S. Ang, and I. C. Botero, "Conceptualizing Employee Silence and Employee Voice as Multidimensional Constructs*," J. Manag. Stud., vol. 40, no. 6, pp. 1359-1392, 2003.

[14] C. Pinder and K. Harlos, "Employee Silence: Quiescence and Acquiescence as Responses to Perceived Injustice," in Research in Personnel and Human Resources Management, vol. 20, 2001, pp. 331-369.

[15] J. Kish-Gephart, J. Detert, L. Treviño, and A. Edmondson, "Silenced by fear," Res. 
Organ. Behav. - RES ORGAN BEH, vol. 29, pp. 163-193, Dec. 2009.

[16] J. Pierce, D. Gardner, L. Cummings, and R. Dunham, "Organization-based self-esteem: Construct definition, measurement, and validation," Acad. Manag. J., vol. 32, pp. 622648, Sep. 1989.

[17] J. Mathieu and S. Taylor, "A Framework for Testing Meso-Mediational Relationships in Organizational Behavior,” J. Organ. Behav., vol. 28, pp. 141-172, Feb. 2007.

[18] L. Fry, “Toward a Theory of Spiritual Leadership," Leadersh. Q., vol. 14, pp. 693-727, Dec. 2003.

[19] L. W. Fry, S. Vitucci, and M. Cedillo, "Spiritual leadership and army transformation: Theory, measurement, and establishing a baseline," Leadersh. Q., vol. 16, no. 5, pp. 835862, 2005.

[20] C. Chen, C. Yang, and C. Li, "Spiritual Leadership, Follower Mediators, and Organizational Outcomes: Evidence From Three Industries Across Two Major Chinese Societies," J. Appl. Soc. Psychol., vol. 42, Apr. 2012.

[21] C.-Y. Chen and C.-I. Li, "Assessing the spiritual leadership effectiveness: The contribution of follower's self-concept and preliminary tests for moderation of culture and managerial position," Leadersh. Q., vol. 24, pp. 240-255, Feb. 2013.

[22] C. Y. Chen and C. F. Yang, "The Impact of Spiritual Leadership on Organizational Citizenship Behavior: A Multi-Sample Analysis,” J. Bus. Ethics, vol. 105, no. 1, pp. 107-114, 2012.

[23] A. Pekerti and S. Sendjaya, "Exploring servant leadership across cultures: Comparative study in Australia and Indonesia," Int. J. Hum. Resour. Manag., vol. 21, Apr. 2010.

[24] S. Kirpal, "Researching work identities in a European context," Career Dev. Int., vol. 9, no. 3, pp. 199-221, 2004.

[25] L. Fry and J. Slocum, "Maximizing the Triple Bottom Line through Spiritual Leadership," Organ. Dyn. - ORGAN DYN, vol. 37, Jan. 2008.

[26] L. Fry, S. Hannah, and M. Noel, "Impact of spiritual leadership on unit performance [RETRACTED]," Leadersh. Q., vol. 22, Apr. 2011.

[27] A. O. Hirschman, Exit, Voice, and Loyalty: Responses to Decline in Firms, Organizations, and States. Cambridge: Harvard University Press, 1970.

[28] F. O. Walumbwa and J. Schaubroeck, "Leader personality traits and employee voice behavior: Mediating roles of ethical leadership and work group psychological safety.," Journal of Applied Psychology, vol. 94, no. 5. American Psychological Association, Walumbwa, Fred O.: Department of Management, W. P. Carey School of Business, Arizona State University, Tempe, AZ, US, 85287-4006, fred.walumbwa@asu.edu, pp. 1275-1286, 2009.

[29] S. Tangirala and R. Ramanujam, "Employee Silence on Critical Work Issues: The Cross Level Effects of Procedural Justice Climate,” Pers. Psychol., vol. 61, pp. 37-68, Feb. 2008.

[30] J. Zhou and J. M. George, "When job dissatisfaction leads to creativity: Encouraging the expression of voice.," Acad. Manag. J., vol. 44, no. 4, pp. 682-696, 2001.

[31] P. Podsakoff, S. MacKenzie, J. Paine, and D. Bachrach, "Organizational Citizenship Behaviors: A Critical Review of the Theoretical and Empirical Literature and Suggestions for Future Research,” J. Manage., vol. 26, pp. 513-563, Jul. 2013.

[32] J. R. Detert and E. R. Burris, "Leadership behavior and employee voice: Is the door really open?," Acad. Manag. J., vol. 50, no. 4, pp. 869-884, 2007.

[33] W. Liu, R. Zhu, and Y. Yang, "I warn you because I like you: Voice behavior, employee identifications, and transformational leadership,” Leadersh. Q., vol. 21, pp. 189-202, 
Feb. 2010.

[34] J. Fuller, Barnett, K. Hester, and Frey, “An exploratory examination of voice behavior from a impression management perspective," J. Manag. Issues, vol. 19, pp. 134-151., Mar. 2007.

[35] M. Rahim, “The Development of a Leader Power Inventory," Multivar. Behav. Res. Multivar. BEHAV RES, vol. 23, pp. 491-503, Oct. 1988.

[36] M. Rahim and G. Buntzman, "Supervisory Power Bases, Styles of Handling Conflict With Subordinates, and Subordinate Compliance and Satisfaction," J. Psychol. Interdiscip. Appl., vol. 133, pp. 195-210, Mar. 1989.

[37] Z. Aycan et al., "Impact of Culture on Human Resource Management Practices: A 10Country Comparison," Appl. Psychol. Int. Rev. Appl. Int. - APPL PSYCHOL-INT REV, vol. 49, pp. 192-221, Jan. 2000.

[38] J. Barling, A. Christie, and N. Turner, "Pseudo-Transformational Leadership: Towards the Development and Test of a Model," J. Bus. Ethics, vol. 81, pp. 851-861, Feb. 2008.

[39] S. Premeaux and A. Bedeian, "Breaking the Silence: The Moderating Effects of Self-Monitoring in Predicting Speaking Up in the Workplace*," J. Manag. Stud., vol. 40, pp. 1537-1562, Sep. 2003.

[40] C. Tröster and D. Knippenberg, "Leader openness, nationality dissimilarity, and voice in multinational management teams," J. Int. Bus. Stud., vol. 43, Aug. 2012.

[41] J. Gooty, M. Gavin, and N. Ashkanasy, "Emotions Research in OB: The Challenges That lie Ahead," J. Organ. Behav., vol. 30, Aug. 2009.

[42] T. Bauer and S. Green, "Development of leader-member exchange: A longitudinal test. Academy of Management Journal, 39, 1538-1567," Acad. Manag. J., vol. 39, pp. 1538 1567, Dec. 1996.

[43] R. C. Liden, R. T. Sparrowe, and S. J. Wayne, "Leader-member exchange theory: The past and potential for the future.," in Research in personnel and human resources management, Vol. 15., US: Elsevier Science/JAI Press, 1997, pp. 47-119.

[44] B. Emans, L. Munduate, E. Klaver, and E. Vliert, "Constructive Consequences of Leaders’ Forcing Influence Styles,” Appl. Psychol., vol. 52, pp. 36-54, Jan. 2003. 